\title{
Can the Three-Dimensional Heads-Up Display Improve Ergonomics, Surgical Performance, and Ophthalmology Training Compared to Conventional Microscopy?
}

This article was published in the following Dove Press journal: Clinical Ophthalmology

\section{Halah Bin Helayel (DI ${ }^{\prime}$ Sarah Al-Mazidi ${ }^{2}$ \\ Adel AlAkeely ${ }^{3}$}

'Research Department, King Khaled Eye Specialist Hospital, Riyadh, Saudi Arabia; ${ }^{2}$ Department of Physiology, College of Medicine, Al-Imam Mohammed Bin Saud Islamic University, Riyadh, Saudi Arabia; ${ }^{3}$ Vitreoretinal Division, King Khaled Eye Specialist Hospital, Riyadh, Saudi Arabia

Correspondence: Adel AIAkeely Vitreoretinal Division, King Khaled Eye Specialist Hospital, Uruba Road, Riyadh,

I 1 462, Saudi Arabia

Tel +966I I482I 234

Email Aakeely@kkesh.med.sa
Purpose: To explore ophthalmic surgeons' opinions regarding three-dimensional heads-up display (3D HUD) use and investigate musculoskeletal (MSK) complaints among ophthalmologists.

Methods: Physicians were invited to complete an online questionnaire. Musculoskeletal complaints and data of the HUD system use were correlated with demographic information. We explored surgeons' feedback on image quality, depth perception, and the educational value of 3D microscopy.

Results: In this study, the prevalence of self-reported MSK pain was $82.6 \%(n=132)$. The pain started after joining ophthalmology practice and significantly improves on weekends and vacations. We found that the pain intensity in non-HUD users is higher than in HUD users, but this correlation was not statistically significant. Sixty-one (84.7\%) of HUD system users were satisfied with depth perception, and 27 (37.5\%) reported improvement in peripheral acuity. Thirty-seven (51.4\%) of the participants believed they perform surgeries better through HUD; this was why most participants $(83.3 \%)$ recommended its use in surgical training.

Conclusion: Heads-up display use provides more comfortable sitting positions for surgeons, superior depth perception, and serves as a better educational tool. We believe that adopting this technology may help improve career longevity and productivity.

Keywords: ergonomics, heads-up display, three-dimensional visualization, ophthalmic surgery

\section{Introduction}

Musculoskeletal disorders (MSK Disorders) are prevalent among ophthalmologists. ${ }^{1-4}$ Long-term use of conventional microscopy is associated with MSK discomfort and fatigue, which can limit the surgeons' career longevity leading to early retirement. 5,6

Fortunately, new technology such as the three-dimensional (3D) display systems allows surgeons to perform surgery with more comfort by viewing the microscopic image on a large screen, allowing surgeons to operate in a "heads-up" position; a more natural body posture. The HUD system also can allow the surgeon to move freely without compromising the image quality ${ }^{7}$ Figure 1 . The HUD system offers more benefits over the conventional ophthalmic microscope by allowing good visualization with lower illumination levels, enhanced depth perception, presence of an integrated 
A

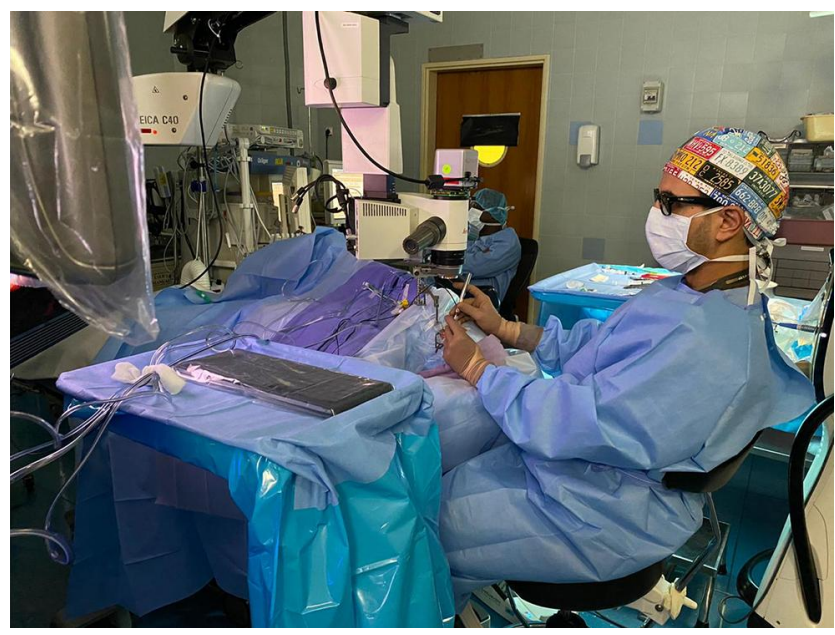

B

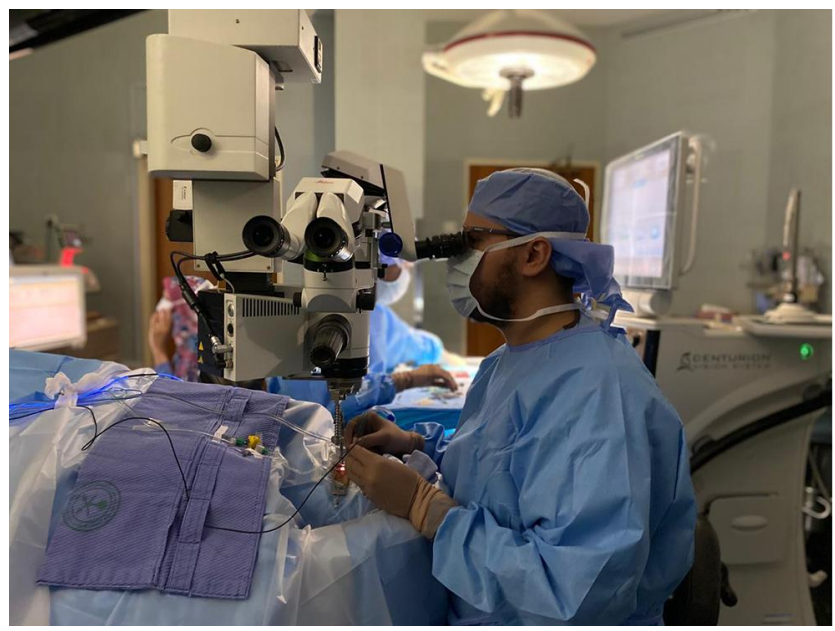

Figure I (A) Image showing a surgeon (Author A.A.) performing surgery through a heads-up display system. (B) Image showing a surgeon performing surgery through the conventional ophthalmic microscope (Courtesy of Dr Faisal AIQahtani, vitreoretinal division, KKESH). The surgeon in figure IB provided informed consent for the image to be published.

vitrectomy or phacoemulsification machine data feedback, and providing similar visualization of the surgery for both primary surgeon and assistant surgeon as well as other staff in the operating theater. ${ }^{8-10}$ The HUD system also provides similar surgical duration, visual outcomes, and complication rates compared to conventional surgery. ${ }^{7,11}$ Additionally, the large screen offers better use of intraoperative OCT device (iOCT) that can be fully integrated into the HUD system without limiting the surgeons' view as in the case of iOCT mounted conventional microscope. ${ }^{12}$

This study aimed to evaluate the factors that may make the 3D heads-up display a better alternative to conventional microscopy in improving ergonomic, image quality, and educational experience.

\section{Methods}

The current study was approved by the institutional review board at King Khaled Eye Specialist Hospital (KKESH) (number: 2081-P). All study conducts adhere to the tenets of the Declaration of Helsinki. A cross-sectional survey was conducted through an online self-administered 28items questionnaire (Appendix 1) between July 2 and 20, 2020. The study participants included ophthalmology consultants, fellows, and residents. Participation was voluntary, complete anonymity was ensured, and participants provided informed consent. The survey was distributed using professional social media platforms (LinkedIn) or direct invitation through text messages or WhatsApp.
The survey included data on demographic characteristics (age, gender, height, weight, and physical activity level), years of practice in the ophthalmology field, subspecialty, number of cases performed using HUD, weekly hours spent in surgery, and factors that might lead to adopting 3D technology in both technical and educational point of view.

\section{Statistical Analysis}

Statistical analysis was performed using SPSS version 26.0 (IBM Software). Continuous variables were tested for normality using the Shapiro-Wilk test, and then they were expressed as mean and standard deviation (SD). Student's $t$-test was used to examine the association between continuous variables (age, body mass index (BMI), and pain intensity) and the use of the HUD system and pain experience. Categorical variables were summarized as frequencies and percentages. The associations between categorical variables were tested using Pearson's Chi-squared or Fisher-Freeman-Halton exact tests as appropriate. Significance was denoted as: $* P<0.05$; $* * P<0.01 ; * * * P<0.001$.

\section{Results}

One hundred and forty ophthalmic surgeons participated in this study. The study demographics are shown in Table 1. Fifty-seven percent of the participants were at the consultant level. Around $65 \%$ of the overall participants were vitreoretinal surgeons. Two-thirds of the participants had 
Table I Characteristics of the Study Participants $(n=149)$

\begin{tabular}{|c|c|c|}
\hline Characteristics & $\mathbf{N}$ & $\%$ \\
\hline Age (years) Mean $\pm S D$ & \multicolumn{2}{|c|}{$36.7 \pm 9.7$} \\
\hline \multicolumn{3}{|l|}{ Sex } \\
\hline Male & 112 & 75.2 \\
\hline Female & 37 & 24.8 \\
\hline BMI $\left(\mathbf{k g} / \mathbf{m}^{2}\right) *$ Mean $\pm S D$ & \multicolumn{2}{|c|}{$25.1 \pm 3.6$} \\
\hline \multicolumn{3}{|l|}{ Subspecialty } \\
\hline Retina & 84 & 56.4 \\
\hline Other & 65 & 43.6 \\
\hline \multicolumn{3}{|l|}{ Experience (years) } \\
\hline $1-10$ & 99 & 66.4 \\
\hline$\geq I I$ & 50 & 33.6 \\
\hline \multicolumn{3}{|l|}{ Current surgeon level } \\
\hline Resident & 34 & 22.8 \\
\hline Fellow & 29 & 19.5 \\
\hline Consultant & 85 & 57.0 \\
\hline Prevalence of pain & 123 & 82.6 \\
\hline
\end{tabular}

Abbreviation: *BMI, body mass index.

10 years or less experience in the ophthalmology field. Despite $65 \%$ of the participants reporting they are aware of the importance of workplace ergonomics, the prevalence of self-reported pain in this study was $82.6 \%$ (123 participants) (Table 2). Of those, $78.9 \%$ stated their MSK complaints started after joining ophthalmology ( $p$-value $<0.001$ ), and $76 \%$ reported that their pain was alleviated during weekends and vacations ( $p$-value $<0.001)$. Twothirds of participants reported that this pain affected their daily activities. Participants also reported that pain is mostly localized in the lower back and neck regions. We found no differences in the self-reported pain locations between the HUD and non-HUD users $(p=0.5)$ (Figure 2). A comparison of means using independent Student's $t$-test was performed to exclude factors associated with MSK pain development, such as age and body mass index, and we found no significant difference. There was an increase in pain intensity with work experience, but this correlation was not statistically significant. Also, pain intensity was equally distributed between ophthalmic subspecialties and did not increase with the number of surgeries performed weekly.

Participants were then divided into two groups (HUD users and non-HUD users) to evaluate the factors that
Table 2 Risk Factors of Musculoskeletal Pain Among Participants

\begin{tabular}{|c|c|c|c|}
\hline & \multicolumn{2}{|c|}{$\begin{array}{l}\text { Have You Experienced } \\
\text { Musculoskeletal Pain in } \\
\text { the Past } 5 \text { Years? }\end{array}$} & \multirow[t]{2}{*}{$P$} \\
\hline & $\begin{array}{l}\text { Total }(n= \\
\text { 149) }\end{array}$ & $\begin{array}{l}\text { Yes } \\
(n=123)\end{array}$ & \\
\hline $\begin{array}{l}\text { Pain before ophthalmology } \\
\text { service }\end{array}$ & & & $<0.001$ \\
\hline Yes & 26 & 26 & \\
\hline No & 97 & 97 & \\
\hline \multicolumn{4}{|l|}{ Subspecialty } \\
\hline Retina & 84 & 69 & \\
\hline Cornea & 19 & 18 & \\
\hline Glaucoma & 8 & 5 & \\
\hline Comprehensive & 4 & 4 & \\
\hline Pediatric ophthalmology & 2 & 2 & \\
\hline \multicolumn{4}{|l|}{ Experience (years) } \\
\hline $1-5$ & 49 & 38 & \\
\hline $6-10$ & 50 & 44 & \\
\hline $11-15$ & 21 & 17 & \\
\hline $16-20$ & 12 & 10 & \\
\hline $20+$ & 17 & 14 & \\
\hline \multicolumn{4}{|l|}{ Current surgeon level } \\
\hline Resident & 34 & 27 & \\
\hline Fellow & 29 & 24 & \\
\hline Consultant & 85 & 71 & \\
\hline \multicolumn{4}{|l|}{ Surgical volume (hours/week) } \\
\hline$<3$ & 36 & 28 & \\
\hline $3-6$ & 55 & 51 & \\
\hline $7-10$ & 42 & 31 & \\
\hline $11-14$ & 13 & 10 & \\
\hline $15+$ & 3 & 3 & \\
\hline \multicolumn{4}{|l|}{ Activity level (hours/week) } \\
\hline None & 24 & 17 & \\
\hline $\mathrm{I}-3$ & 68 & 59 & \\
\hline 4-6 & 31 & 25 & \\
\hline 7-9 & 11 & 10 & \\
\hline $10+$ & 15 & 12 & \\
\hline $\begin{array}{l}\text { Pain decreases during weekends } \\
\text { and vacations }\end{array}$ & & & $<0.001$ \\
\hline Yes & 94 & 94 & \\
\hline No & 29 & 29 & \\
\hline Impact on QoL* & & & $<0.001$ \\
\hline Yes & 41 & 41 & \\
\hline No & 82 & 82 & \\
\hline \multicolumn{4}{|l|}{$\begin{array}{l}\text { Knowledge of workplace } \\
\text { ergonomics }\end{array}$} \\
\hline Yes & 97 & 81 & \\
\hline No & 52 & 42 & \\
\hline
\end{tabular}

Abbreviation: *QoL, quality of life. 


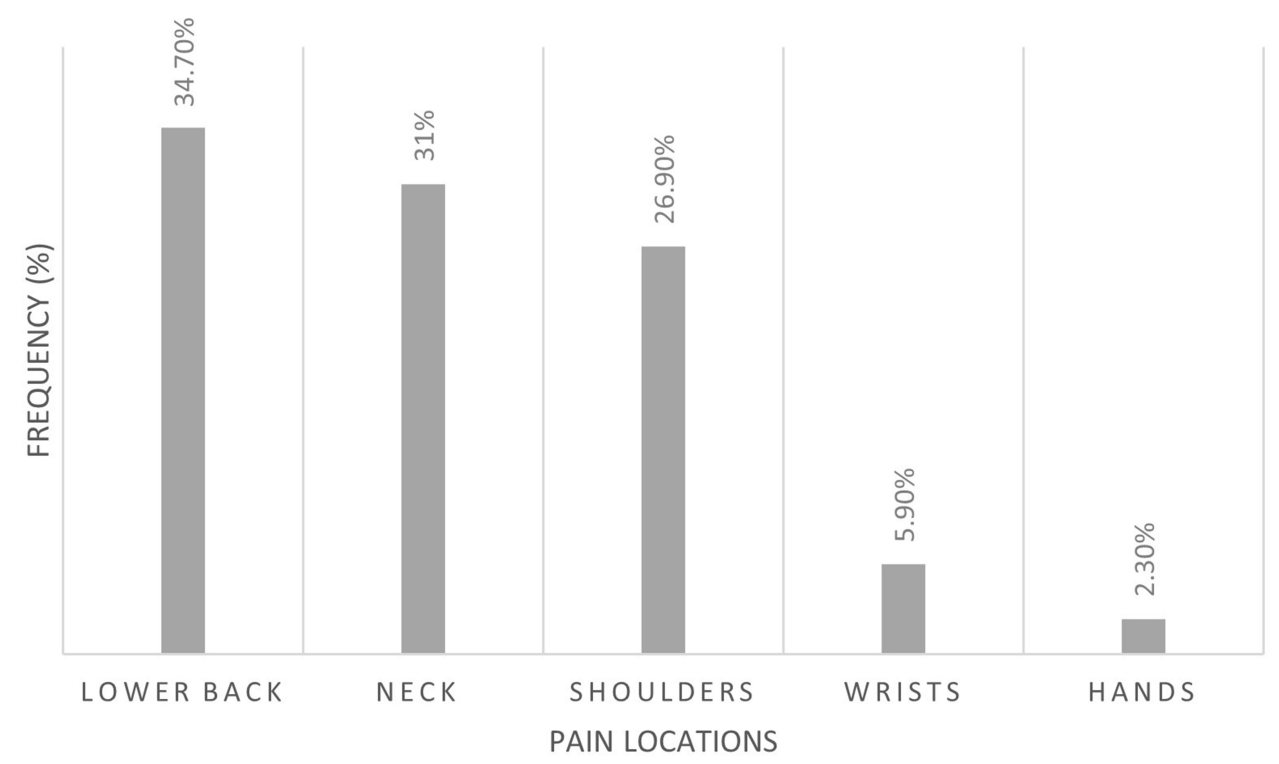

Figure 2 Self-reported pain locations according to the study participants $(n=123)$.

might affect image quality, teaching experience, and surgeons' posture during surgery to prevent MSK disorders. Table 3 summarizes the characteristics of HUD users and non-HUD users. The majority of the HUD users were Vitreoretinal surgeons $(\mathrm{n}=59,81.9 \%)$, and most of them were consultants $(n=48,66.7 \%)$. Figure 3 shows that HUD users $(9.60 \pm 4.85)$ had a significantly higher level of experience compared to non-HUD users $(6.80 \pm 4.09)$ $(p<0.01)$. The number of surgeries per week was significantly higher in HUD users (7.43 \pm 3.15$)$ compared to non-HUD users $(3.78 \pm 2.83)(\mathrm{p}<0.001)$ (Figure 4). Also, these data suggest there was a trend that pain intensity in non-HUD users $(3.92 \pm 2.26)$ is higher than in HUD users (3.64 \pm 2.51$)$, but this correlation was not statistically significant

$(\mathrm{P}=0.16)$.

Regarding HUD users' experience feedback, 27 (37.5\%) found that the peripheral acuity is better in the HUD system than conventional microscopy. Sixty-one (84.7\%) of HUD users found the depth perception is better. Thirty-seven $(51.4 \%)$ of the participants believed that they perform surgeries better through HUD in conjunction with the currently available instruments, such as small incision vitrectomy instruments and machines. Forty-nine (68.1\%) of the HUD users found it a valuable educational tool. Also, 60 (83.3\%) users recommended its use in surgical training, and $50(69.4 \%)$ recommended using it in general (Table 4).

\section{Discussion}

Ophthalmologists are vulnerable to work-related MSK disorders due to the nature of their work, which requires repetitive tasks in non-neutral postures for a long time, including performing examinations at the slit-lamp, using indirect ophthalmoscopy or performing surgeries using the operative microscope.$^{13}$ Interestingly, these tasks were found to require greater muscular demands compared to other activities such as computer use for documentation, applying drops to the patients, or checking visual acuity. ${ }^{14}$ The American Academy of Ophthalmology provides many resources and online courses to address workplace ergonomics. ${ }^{15}$ Most of the ophthalmologists who reported pain were aware of the importance of workplace ergonomics.

Similar to other reports, we found that the prevalence of MSK pain among ophthalmologists is high (78.5\%) and is higher among consultants with a higher level of experience. Also, we found this pain is alleviated during vacations and was less in individuals who exercised regularly. ${ }^{1-4,16}$

Modification of posture during surgery is essential to protect against MSK disorders. However, Droezea and Jonssonb reported that difficulties in changing old routines are the most commonly reported barriers among their study participants. ${ }^{17}$ Interestingly, HUD users in our study were aware of the importance of workplace ergonomics. One of the advantages of using the HUD system is that it allows surgeons to operate in a more neutral position. In our study, most HUD users reported that their pain did not increase 
Table 3 Characteristics of the Heads-Up Display System Users and Non-Users

\begin{tabular}{|c|c|c|c|c|c|}
\hline \multirow[t]{3}{*}{ Characteristics } & \multicolumn{4}{|c|}{$\begin{array}{l}\text { Use the Heads-Up } \\
\text { Display System }\end{array}$} & \multirow[t]{3}{*}{$P$} \\
\hline & \multicolumn{2}{|c|}{ Yes (n =72) } & \multicolumn{2}{|c|}{ No $(n=77)$} & \\
\hline & $\mathbf{n}$ & $\%$ & $\mathbf{n}$ & $\%$ & \\
\hline Subspecialty & & & & & 0.001 \\
\hline Retina & 59 & 70.2 & 25 & 29.8 & \\
\hline Cornea & 5 & 26.3 & 14 & 73.7 & \\
\hline Glaucoma & 3 & 37.5 & 5 & 62.5 & \\
\hline Comprehensive & 2 & 50 & 2 & 50 & \\
\hline Pediatric ophthalmology & & & 2 & 100 & \\
\hline Experience (years) & & & & & 0.003 \\
\hline $\mathrm{I}-5$ & 14 & 28.6 & 35 & 71.4 & \\
\hline $6-10$ & 26 & 52.0 & 24 & 48.0 & \\
\hline $11-15$ & 15 & 71.4 & 6 & 28.6 & \\
\hline $16-20$ & 9 & 75.0 & 3 & 25.0 & \\
\hline $20+$ & 8 & 47.1 & 9 & 52.9 & \\
\hline Current surgeon level & & & & & $<0.001$ \\
\hline Resident & 4 & 11.8 & 30 & 88.2 & \\
\hline Fellow & 20 & 69.0 & 9 & 31.0 & \\
\hline Consultant & 48 & 56.5 & 37 & 43.5 & \\
\hline Hours in surgery/week & & & & & $<0.001$ \\
\hline$<3$ & 4 & 11.1 & 32 & 88.9 & \\
\hline $3-6$ & 23 & 41.8 & 32 & 58.2 & \\
\hline $7-10$ & 30 & 71.4 & 12 & 28.6 & \\
\hline $11-14$ & 12 & 92.3 & 1 & 7.7 & \\
\hline $15+$ & 3 & 100 & & & \\
\hline Pain location & & & & & 0.5 \\
\hline Neck & 32 & 32.3 & 35 & 30.2 & \\
\hline Lower back & 31 & 31.3 & 44 & 37.9 & \\
\hline Shoulders & 28 & 28.3 & 30 & 25.9 & \\
\hline Wrists & 6 & 6.1 & 5 & 4.3 & \\
\hline Hands & 2 & 2 & 2 & 1.7 & \\
\hline
\end{tabular}

when using the HUD system. This finding was also reported in a previous study. ${ }^{6}$ Although HUD users had significantly higher working experience and more hours of surgeries per week than non-HUD users, the HUD users' pain was similar to non-HUD users, indicating that HUD might be more ergonomically friendly for ophthalmologists.

Depth perception is very important during vitreoretinal surgery, particularly macular surgeries. It can ensure procedure safety and also facilitate bimanual techniques. Consistent with previously published studies, most of our participants believed that the HUD system provides better depth perception than traditional microscopy. ${ }^{6-8,10,18}$ Visualization of peripheral retina is critical during vitreoretinal procedures, especially

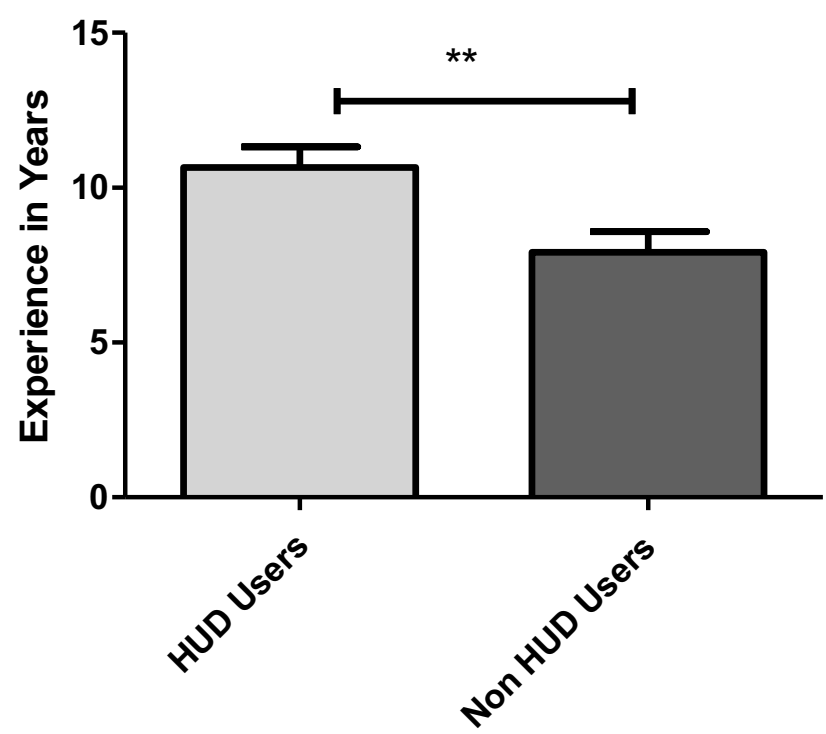

Figure 3 Level of experience among HUD users vs non-HUD users $(* * P<0.01)$.

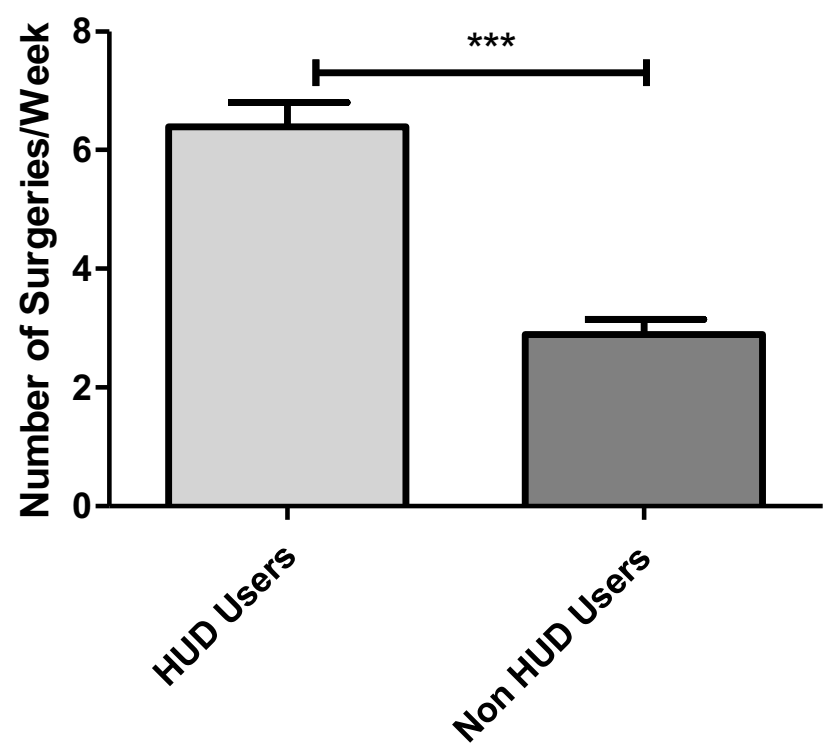

Figure 4 The number of surgeries performed weekly in HUD users vs non-HUD users $(* * * P<0.001)$.

during vitreous base shaving near the ora serrata and during peripheral retina examination before concluding the surgery. Our results were consistent with a previous report by Agranat et al, which showed that peripheral acuity through HUD is at least good as conventional microscopy. ${ }^{10}$ Our results also indicate no issue with integrating the HUD system with the currently used equipment, eg, vitrectomy machine and forceps. Also, two-third of the HUD users found the device technically feasible. In the pilot study by Talcott et al, they reported longer peel time and less ease of use during macular surgery that was attributed to the learning curve of this new technology. 
Table 4 Performance of the Heads-Up Display System Compared to the Conventional Ophthalmic Microscope $(n=72)$

\begin{tabular}{|l|l|l|l|}
\hline \multicolumn{2}{|l|}{ Characteristics } & n & $\%$ \\
\hline Peripheral acuity & Better & 27 & 37.5 \\
& Worse & 16 & 22.2 \\
& No difference & 29 & 40.3 \\
\hline Depth perception & Better & 61 & 84.7 \\
& Worse & 5 & 6.9 \\
\hline Integration with current & No difference & 6 & 8.3 \\
\hline ophthalmic equipment & Better & 37 & 51.4 \\
\hline Educational value & Worse & 11 & 15.3 \\
& No difference & 24 & 33.3 \\
\hline Recommended using & Better & 49 & 68.1 \\
HUD* generally & Worse & 1 & 1.4 \\
HUD* in education & Maybe & 5 & 6.9 \\
& Not applicable (not & 17 & 23.6 \\
\hline involved in training) & & \\
\hline Nes & No & 30 & 83.3 \\
& No & 9 & 12.5 \\
\hline & Neutral & 50 & 69.4 \\
& Neutral & 20 & 27.8 \\
\hline
\end{tabular}

Note: *Heads-up display.

However, their finding was not associated with overall longer surgical duration and higher complications rate when compared to the conventional microscope. ${ }^{19}$

Our findings support our belief that HUD has superior educational value. Most HUD users in our study, including trainees, believed that the system performs better during surgical teaching than the traditional microscope. Assistants and trainees can see the same view as the primary surgeon, allowing better communication and understanding. ${ }^{11,20}$ It can also facilitate instruction only by moving the pointer to the area of interest to show where pathology is located and where the surgical maneuver is needed. ${ }^{21}$ Because of the HUD's advantages as an educational tool, most HUD users in our report recommended its use as a teaching tool. The experiment conducted by Eckardt and Paulo demonstrated that learning to operate using HUD is not difficult. In their study, they included participants who had no experience with microsurgery. However, participants felt that HUD use is easier or no different than the traditional microscope in performing tasks given by the researchers. ${ }^{7}$

The first ophthalmic procedure performed by the 3D display system was an anterior segment procedure; cataract surgery, in $2009 .^{22}$ Nevertheless, there was a relative delay in adopting this technology by the anterior segment surgeons. This could be due to 80-ms latency present in the older versions; however, this issue has been nearly eliminated in the most recent platform. ${ }^{23}$ In his recent study, Weinstock et al found that performing cataract surgery with HUD was as safe and effective as the conventional microscope with a similar complication rate. ${ }^{11}$ Anterior segment surgeons who participated in our study who used HUD also believe that this technology performs better in terms of peripheral acuity, depth perception, and surgical education compared to conventional microscopy. Also, visualization using HUD provides a more detailed view, even with higher magnification. Each layer stays clear regardless of the depth of focus. This ability was found advantageous during critical steps of the Descemet membrane endothelial keratoplasty (DMEK) procedure, such as determining the correct position of the Descemet membrane roll. $^{24}$

Interestingly, we observed that those between 11 and 20 years of experience are more likely to adopt this technology and can be categorized according to the diffusion of innovations theory by E. M. Roger's in 1962 into early adaptors or early majority. ${ }^{25}$ We speculate this might be related to the fact that they are more comfortable at this stage of their career. Therefore, they are more open to adopting new techniques and technologies. Another explanation of adopting HUD in this group might be related to their own experience of MSK problems after many years of using conventional microscopes and high surgical volume, thereby shifting to a more ergonomic option. A major hurdle in adopting this technology is its cost, and several of our participants do not seem to find the cost justified when used outside academic institutions. ${ }^{10}$ One of the participants in this study complained of diplopia when using the system and reported that this issue would prevent using this technology again. One explanation of this phenomenon might be related to the vergence-accommodation conflicts theory by Hoffman et al (2008). The idea behind this theory is while using the 3D display systems; the vergence stimulus varies depending on where the viewer looks while the focal distance remains fixed; the difference in those distances requires an effort to overcome the normal coupling between vergence and accommodation, and this effort appears to lead to visual fatigue and discomfort. ${ }^{26}$ Another explanation could be the exacerbation of preexistent exophoria in the user while operating through the $3 \mathrm{D}$ visualization system. ${ }^{27}$ Also, Terzić and Hansard discussed many other visual discomfort reasons while using stereoscopic 3D display systems. These factors include crosstalk or ghosting (incomplete separation of both eyes 
images), inappropriate disparity (misalignments or mismatches between the left and right views), in-depth motion, and the puppet theatre effect (inconsistent retinal disparity cues with the expected sizes of observed objects). ${ }^{28}$ In their casecontrol study, Zhang et al reported three main difficulties during surgery through HUD. These difficulties occurred with the movement of the patient's head during scleral indentation, surgeon disturbance by amplified opacity located in the cornea, anterior, or posterior lens capsule, and nausea and dizziness experienced when performing prolonged laser photocoagulation. However, the authors reported complaint resolution after a short break without switching to the conventional microscope. $^{29}$

The current study is limited by its cross-sectional design, small sample size, and participants' self-selection. Also, our survey did not include other less commonly reported side effects of HUD, such as eye fatigue or experience of motion sickness. Likewise, we did not include questions about participants' opinions on performance of some manual surgical techniques like suturing while using HUD vs conventional microscopy. However, this is the first study to report factors that might lead to a better surgical and educational experience for surgeons and trainees and their possible role in preventing MSD among ophthalmologists.

In conclusion, many ophthalmologists using the heads-up $3 \mathrm{D}$ visualization display found the system has better ergonomics, superior visualization, and improved training experience. According to our data, musculoskeletal complaints remain a problem among ophthalmologists, even in HUD users. Institutions should focus on solutions to improve the workplace environment and reducing occupational hazards while progressing in the field.

\section{Presentation}

Date and place of presentation: This work has not been presented in the past.

\section{Funding}

Disclosure of any funding: NA.

\section{Disclosure}

The authors report no conflicts of interest for this work.

\section{References}

1. Al-Marwani Al-Juhani M, Khandekar R, Al-Harby M, Al-Hassan A, Edward DP. Neck and upper back pain among eye care professionals. Occup Med (Lond). 2015;65(9):753-757. doi:10.1093/occmed/kqv132
2. Venkatesh R, Kumar S. Back pain in ophthalmology: national survey of Indian ophthalmologists. Indian $J$ Ophthalmol. 2017;65 (8):678-682. doi:10.4103/ijo.IJO_344_17

3. Hyer JN, Lee RM, Chowdhury HR, Smith HB, Dhital A, Khandwala M. National survey of back \& neck pain amongst consultant ophthalmologists in the United Kingdom. Int Ophthalmol. 2015;35(6):769-775. doi:10.1007/s10792-015-0036-z

4. Dhimitri KC, McGwin G Jr, McNeal SF, et al. Symptoms of musculoskeletal disorders in ophthalmologists. Am J Ophthalmol. 2005;139 (1):179-181. doi:10.1016/j.ajo.2004.06.091

5. Epstein S, Sparer EH, Tran BN, et al. Prevalence of work-related musculoskeletal disorders among surgeons and interventionalists: a systematic review and meta-analysis. JAMA Surg. 2018;153(2): e174947. doi:10.1001/jamasurg.2017.4947

6. Mendez BM, Chiodo MV, Vandevender D, Patel PA. Heads-up 3D microscopy: an ergonomic and educational approach to microsurgery. Plast Reconstr Surg Glob Open. 2016;4(5):e717. doi:10.1097/ GOX.0000000000000727

7. Eckardt C, Paulo EB. Heads-up surgery for vitreoretinal procedures: an experimental and clinical study. Retina. 2016;36(1):137-147. doi:10.1097/IAE.0000000000000689

8. Palacios RM, de Carvalho ACM, Maia M, Caiado RR, Camilo DAG, Farah ME. An experimental and clinical study on the initial experiences of Brazilian vitreoretinal surgeons with heads-up surgery. Graefes Arch Clin Exp Ophthalmol. 2019;257(3):473-483. doi:10.1007/s00417-019-04246-w

9. Matsumoto CS, Shibuya M, Makita J, et al. Heads-up 3D surgery under low light intensity conditions: new high-sensitivity HD camera for ophthalmological microscopes. $J$ Ophthalmol. 2019;2019:5013463. doi:10.1155/2019/5013463

10. Agranat JS, Miller JB, Douglas VP, et al. The scope of three-dimensional digital visualization systems in vitreoretinal surgery. Clin Ophthalmol. 2019;13:2093-2096. doi:10.2147/OPTH. S213834

11. Weinstock RJ, Diakonis VF, Schwartz AJ, Weinstock AJ. Heads-up cataract surgery: complication rates, surgical duration, and comparison with traditional microscopes. $J$ Refract Surg. 2019;35 (5):318-322. doi:10.3928/1081597X-20190410-02

12. Ehlers JP, Uchida A, Srivastava SK. The integrative surgical theater: combining intraoperative optical coherence tomography and 3D digital visualization for vitreoretinal surgery in the discover study. Retina. 2018;38(Suppl 1):S88-S96. doi:10.1097/ IAE.0000000000001999

13. Shaw C, Bourkiza R, Wickham L, McCarthy I, McKechnie C. Mechanical exposure of ophthalmic surgeons: a quantitative ergonomic evaluation of indirect ophthalmoscopy and slit-lamp biomicroscopy. Can J Ophthalmol. 2017;52(3):302-307. doi:10.1016/j.jcjo.2016.09.011

14. Fethke NB, Schall MC, Determan EM, Kitzmann AS. Neck and shoulder muscle activity among ophthalmologists during routine clinical examinations. Int $J$ Ind Ergon. 2015;49:53-59. doi:10.1016/ j.ergon.2015.06.001

15. Ergonomics. Available from: https://www.aao.org/search/results?q= Ergonomics\&realmName $=$ HTTP\&wt $=$ json\&rows $=10 \&$ start $=0$. Accessed September 9, 2020.

16. Chatterjee A, Ryan WG, Rosen ES. Back pain in ophthalmologists. Eye (Lond). 1994;8(Pt 4):473-474. doi:10.1038/eye.1994.112

17. Droeze EH, Jonsson H. Evaluation of ergonomic interventions to reduce musculoskeletal disorders of dentists in the Netherlands. Work. 2005;25(3):211-220.

18. Coppola M, La Spina C, Rabiolo A, Querques G, Bandello F. Headsup 3D vision system for retinal detachment surgery. Int J Retin Vitr. 2017;3(1):46. doi:10.1186/s40942-017-0099-2

19. Talcott KE, Adam MK, Sioufi K, et al. Comparison of a three-dimensional heads-up display surgical platform with a standard operating microscope for macular surgery. Ophthalmol Retina. 2019;3(3):244-251. doi:10.1016/j.oret.2018.10.016 
20. Romano MR, Cennamo G, Comune C, et al. Evaluation of 3D heads-up vitrectomy: outcomes of psychometric skills testing and surgeon satisfaction. Eye (Lond). 2018;32(6):1093-1098. doi:10.1038/s41433-018-0027-1

21. Palacios RM, Maia A, Farah ME, Maia M. Learning curve of three-dimensional heads-up vitreoretinal surgery for treating macular holes: a prospective study. Int Ophthalmol. 2019;39(10):2353-2359. doi:10.1007/s10792-019-01075-y

22. Weinstock RJ. Heads up cataract surgery with the true vision $3 \mathrm{D}$ display system. In: Weinstock RJ, editor. Surgical Techniques in Ophthalmology-Cataract Surgery. New Delhi, India: JaypeeHighlights Medical Publishers, Inc; 2009:124-128.

23. Moura-Coelho N, Henriques J, Nascimento J, Dutra Medeiros M. Three-dimensional display systems in ophthalmic surgery - a review. Eur Ophthal Rev. 2019;13(1):31-36. doi:10.17925/EOR.2019.13.1.31

24. Panthier C, Courtin R, Moran S, Gatinel D. Heads-up descemet membrane endothelial keratoplasty surgery: feasibility, surgical duration, complication rates, and comparison with a conventional microscope. Cornea. 2020;Publish Ahead of Print. doi:10.1097/ ICO.0000000000002419
25. Rogers E, Singhal A, Quinlan M. Diffusion of Innovations. 2019:182-186.

26. Hoffman DM, Girshick AR, Akeley K, Banks MS. Vergenceaccommodation conflicts hinder visual performance and cause visual fatigue. J Vis. 2008;8(3):3331. doi:10.1167/8.3.33

27. Kim SH, Suh YW, Song JS, et al. Clinical research on the ophthalmic factors affecting 3D asthenopia. J Pediatr Ophthalmol Strabismus. 2012;49(4):248-253. doi:10.3928/01913913-20120207-03

28. Terzić K, Hansard M. Methods for reducing visual discomfort in stereoscopic 3D: a review. Signal Process Image Commun. 2016;47:402-416.

29. Zhang Z, Wang L, Wei Y, Fang D, Fan S, Zhang S. The preliminary experiences with three-dimensional heads-up display viewing system for vitreoretinal surgery under various status. Curr Eye Res. 2019;44 (1):102-109. doi:10.1080/02713683.2018.1526305
Clinical Ophthalmology

\section{Publish your work in this journal}

Clinical Ophthalmology is an international, peer-reviewed journal covering all subspecialties within ophthalmology. Key topics include: Optometry; Visual science; Pharmacology and drug therapy in eye diseases; Basic Sciences; Primary and Secondary eye care; Patient Safety and Quality of Care Improvements. This journal is indexed on PubMed

\section{Dovepress}

Central and CAS, and is the official journal of The Society of Clinical Ophthalmology (SCO). The manuscript management system is completely online and includes a very quick and fair peer-review system, which is all easy to use. Visit http://www.dovepress.com/ testimonials.php to read real quotes from published authors. 